assisted ventilation. Both developed peripheral neuropathy. In case 2 nerve conduction studies and results of electromyography suggested axonal neuropathy, and clinically the two cases were remarkably similar. Muscle wasting was not observed, presumably because of rapid recovery. Postinfective polyneuropathy was unlikely in view of the normal cerebrospinal fluid and nerve conduction velocities.

A "poliomyelitis-like" illness may occur in children with status asthmaticus. ${ }^{4}{ }^{5}$ Our patients, however, were adults, the weakness was symmetrical, and recovery was rapid and complete. In children the neurological deficit is commonly in only one limb, and severe residual flaccid weakness in the affected limb or limbs is the rule. Neither of our patients had been exposed to other toxins or agents known to produce axonal degeneration. Most of the drugs used are in common use for intensive treatment of severe asthma, and the only one not usually included is cimetidine. We suggest that in our patients cimetidine may have been neurotoxic, causing axonal degeneration.

We thank Dr D M Davies for allowing us to report case 1, Dr G Lennox for help with case 1, Dr D D Barwick for the electrophysiological studies in case 2, and Dr N E F Cartlidge for help and advice.

${ }^{1}$ Cohen J, Weetman AP, Dargie HJ, Krikler D. Life-threatening arrhythmias and intravenous cimetidine. $B r$ Med $\mathcal{7} 1979$;ii :768.

2 Isaacs AJ. Cimetidine and thrombocytopenia. $B r \operatorname{Med} \mathcal{F}$ 1980;280:294.

${ }^{3}$ McMillen MA, Ambis D, Siegel JH. Cimetidine and mental confusion. $N$ Engl f Med 1978;298:284.

${ }^{4}$ Hopkins IJ. A new syndrome: poliomyelitis-like illness associated with acute asthma in childhood. Aust Paediatr $\mathcal{F}$ 1974;10:273.

5 Anonymous. Postasthmatic pseudo-polio in children. Lancet $1980 ; \mathrm{i}: 860$.

(Accepted 22 fuly 1980)

Department of Medicine, Dryburn Hospital, Durham DH1 5TW

T J WALLS, BMEDSCI, MRCP, registrar

$S$ J PEARCE, MB, MRCP, consultant physician

University Department of Neurology, Newcastle upon Tyne

G S VENABLES, MA, MRCP, first assistant

\section{"Casualty overload" from the Southall riots}

On 23 April 1979 riots occurred in Southall, Middlesex. Forty-seven casualties were subsequently admitted to the accident and emergency department of Ealing Hospital. We discuss the casualties, their management, and the problems that might arise in an accident and emergency department because of a riot.

\section{Casualties and their injuries}

Of the 47 casualties, 22 were policemen and 25 civilians. Of the four patients with major injuries, one had a head injury and subsequently died, one had head and facial injuries, one had an eye injury, and one a jaw injury. The remaining 43 patients had minor injuries, which included 24 contusions, 21 lacerations, and two penetrating wounds; 31 of these were to the head, 10 to the limbs, and 5 to the trunk. Six patients were admitted, two were transferred to special centres, and one died.

The casualties arrived over seven hours (see figure), the peak occurring between 7 and 8 pm, when 25 casualties arrived.

\section{Special arrangements}

Because of the possibility of riots we made advance arrangements to receive a large number of casualties. The work of the department continued as normal except that the largest treatment area-the stretcher/cubicle area-was taken over for the reception and sorting and emergency treatment of the riot casualties. Minor cases were quickly transferred from the latter area to the minor treatment area, which was next to it. The consultant in charge of the department sorted casualties according to a standard system of priorities into major and minor cases. Of the four major cases admitted, only one was classified as priority 1 -immediate; this was a case of head injury with signs of extradural haemorrhage. There were no urgent cases (priority 2), and the remaining three major cases were non-urgent (priority 3 ).

Staffing-The two senior house officers (SHOs) on duty were allocated to the reception and sorting area, one additional SHO was provided from an

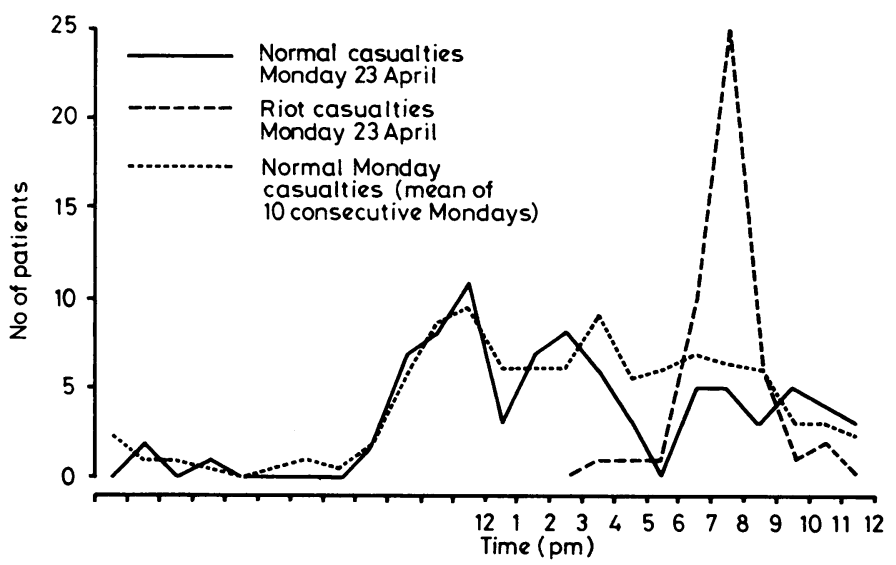

Attendance at accident and emergency department of riot casualties compared with normal work load.

agency to deal with the flow of the normal accident and emergency cases, and an orthopaedic and a paediatric SHO were brought in for the treatment, mainly suturing, of the minor casualties. The anaesthetic SHO was called in for resuscitation duties. The three additional SHOs were on call for the accident and emergency department and remained there for about three and a half hours. The nursing staff cover was normal for peak periods of the day and consisted of two sisters, three staff nurses, and six student nurses. Some of the day staff remained on duty until the incident was cleared. The receptionist on duty was reinforced with three medical records officers, and the two porters on duty were reinforced with four others.

Documentation and equipment-The casualty cards of the casualties were marked with a red asterisk. Documentation was carried out in the reception and sorting area. A police documentation centre was sited in the outpatients department. Because of the minor nature of most of the injuries, no provision was made for extra equipment apart from some extra trolleys, which came from the operating theatre recovery area under an existing arrangement.

\section{Comment}

A major accident ${ }^{1}$ is defined as any incident which requires special arrangements because of the number of casualties. The arrangements to deal with casualties from the Southall riots did not invoke the major accident procedure and were based on the use of the accident and emergency department as a casualty clearing station. They allowed for the economic use of staff, the best use of space and facilities, and adherence to the daily routine as much as possible. Casualties from the riots arrived over seven hours, and our arrangements for dealing with them were adequate, despite a peak flow of 25 cases in one hour.

The commonest injury, both major and minor, resulted from trauma to the head. Although most of the casualties suffered minor injuries, they had to be cleared quickly from the reception area and treated and dispersed as speedily as possible. The main problem in achieving this aim was excluding the possibility of internal injuries or major head injury in patients who arrived in the department frightened, confused, and dazed. In many cases we had to detain patients for observation and subsequent diagnosis rather than delay the management of other apparently more urgent cases waiting to be seen and also to prevent the chaotic consequences that can develop in an overloaded department. For the same reason we paid great attention to the rapid turnover of $x$-ray examinations, the suturing of wounds, the documentation of casualties, and the movement of casualties, with the use of an adequate number of porters.

In discussing disaster procedures Rutherford ${ }^{1}$ refers to people at the site of a bomb explosion being afflicted by a sense of terror and becoming unable to speak or decide what to do. A similar sense of terror must have been engendered at the Southall riots. Lord Moran ${ }^{2}$ distinguished between two states of fear in war: so-called shell shock-what he designated "commotional shock"-and emotional shock, in which a man is frightened only by his thoughts. Most of the casualties from the Southall riots suffered only minor injuries but when first examined could perhaps be described as being in a state of commotional shock. On the other hand, some attendants arriving with the casualties seemed to be afflicted by emotional shock and were overanxious about the casualties. It soon became evident that the relatives of casualties from different factions involved in the riots might behave aggressively towards each other, and at an early stage all relatives were directed to an area isolated from the department. Fortunately, we did not have to segregate walking casualties from 
opposing sides, but there were some signs that such action might be necessary in similar circumstances.

Conclusions-As well as continuing to care for its normal patients an accident and emergency department will have to make special arrangements to prevent the department becoming overloaded with riot casualties. These arrangements should include $(a)$ the use of a large area within the department, preferably next to the minor injury area, for receiving and sorting the riot casualties; $(b)$ the provision of special teams for suturing, extra reception and portering staff, and facilities for rapid $x$-ray examinations; and (c) arrangements for detaining some patients for observation pending diagnosis because the emotional state of the casualties may make diagnosis difficult. There should also be plans for the hospital's security staff to be reinforced by police officers in case of violence among opposing factions within the department. Although it is accepted that when natural disasters produce large numbers of casualties the police should site a documentation team in the accident department, ${ }^{3}$ such action after riots, when criminal proceedings may be pending against some of the casualties, could be construed as a breach of confidentiality. Finally, our experience suggests that the specialised needs of a riot are not catered for by the major accident procedure.

We acknowledge the great help of the nursing staff in dealing with the casualties.

1 Rutherford WH. Surgery of violence. $B r$ Med $\mathcal{F} 1975$;i :443-5.

2 Moran Lord. The anatomy of courage. London: Constable, 1945:21-3.

3 Action for Disaster (International Conference held in Glasgow, April, 1976), page 63 (Police documentation team management).

(Accepted 22 fuly 1980)

Accident and Emergency Department, Ealing Hospital, Southall, Middlesex

N A SHENOUDA, MB, FRCS, consultant in charge (now at the orthopaedic department, Hammersmith Hospital, London W12 0HS)

A D GREIG, MB, BS, senior house officer

A P DIGNAN, MD, FRCs, honorary consultant

\section{Dysentery-like syndrome associated with Aeromonas hydrophila}

Aeromonas hydrophila has been isolated from stools of patients with diarrhoeal disease $\mathrm{e}^{1-3}$ and some of these isolates produce enterotoxin, but its enteropathogenic role is still to be established. ${ }^{4}$ The gastroenteritis associated with this organism is usually self-limiting and does not require treatment. We report here a case of prolonged "dysentery-like" illness in a healthy man associated with repeated recovery of $A$ hydrophila in stool cultures and his cure after treatment with co-trimoxazole.

\section{Case report}

In early December 1979 a 35-year-old Indian doctor developed abdominal cramps and diarrhoea with blood and mucus while on an extensive tour in his own country, which included a visit to Calcutta. Seven days later he returned to the UK. Though the frequency of diarrhoea increased to 5-6 stools/day he remained apyrexial and otherwise well. Examination of two stools, collected one week apart, showed no usual parasitic or bacterial cause except for a moderate growth of sucrose-fermenting, oxidase-positive colonies on thiosulphate bile sucrose agar from the first specimen. This organism identified as $A$ hydrophila using the API-20E system, was not considered significant. As the patient had not had any specific treatment for four weeks he was given a 10-day course of metronidazole on the presumptive diagnosis of amoebic dysentery. This treatment reduced the cramps but did not affect the diarrhoea.

At this stage examination did not show any abnormality except a gross haemorrhagic proctitis found at sigmoidoscopy. A rectal biopsy specimen showed non-specific chronic inflammatory (plasma cell) infiltration of the lamina propria. The appearances on barium enema were normal. The following laboratory tests were negative: routine haematology; liver function tests; serological tests for Epstein-Barr virus, cytomegalovirus, and Entamoeba histolytica; Widal test; and viral culture of stool. Rectal fluid obtained during sigmoidoscopy and a subsequent stool again yielded only a heavy growth of $A$ hydrophila; identification was later confirmed by the Vibrio Reference Laboratory, Maidstone. On disc diffusion testing the isolate was sensitive to all the antimicrobials commonly used against Gram-negative organisms except ampicillin, carbenicillin, and cephaloridine. A high-dose preparation of co-trimoxazole (trimethoprim $160 \mathrm{mg}$ and sulphamethoxazole $800 \mathrm{mg}$ ) was prescribed twice daily for seven days. Within four days of starting treatment the bleeding had stopped but headaches, which the patient attributed to the drug, caused him to discontinue the treatment on the fifth day. Improvement continued and his stools became normal after a further two days. Twelve days after the end of treatment a repeat sigmoidoscopy showed an apparently normal rectum. The results of three stool cultures during the six-week follow-up period were negative and the patient did not have a recurrence.

\section{Comment}

Some workers are convinced that $A$ hydrophila has an enteropathogenic role since it can produce an enterotoxin. Nevertheless, to our knowledge there is only one previous well-documented case of diarrhoeal disease associated with this organism requiring antimicrobial therapy. ${ }^{5}$ The cell-free filtrate of an overnight brain-heart infusion broth culture of our strain examined in the Food Hygiene Laboratory, Colindale, produced appreciable fluid accumulation in ligated rabbit intestines and increased vascular permeability in rabbit skin tests, which suggested that this organism was enterotoxigenic. The isolate also gave a positive lysine decarboxylase test and VogesProskauer reaction, properties which correlate with the production of cytotoxic enterotoxin. ${ }^{4}$ This case of prolonged diarrhoea associated with repeated isolation of $A$ hydrophila from faeces in the absence of any other enteric pathogens, with recovery after appropriate antimicrobial therapy, has provided strong evidence in support of the enteropathogenic role of this species. More studies are needed to elucidate the epidemiology and pathogenesis of this diarrhoeal disease.

We thank Dr A L Furniss, Vibrio Reference Laboratory, Maidstone; Dr P C B Turnbull, Food Hygiene Laboratory, Colindale; and Mrs Foulger for their help.

1 Lautrop A. Aeromonas hydrophila isolated from human faeces and its possible pathological significance. Acta Pathol Microbiol Scand [Suppl] $1961 ; 144: 299-301$.

2 Wadström T, Aust-Kettis A, Habte D, et al. Enterotoxin-producing bacteria and parasites in stools of Ethiopian children with diarrhoeal disease. Arch Dis Child 1976;51:865-70.

3 Annapurna E, Sanyal SC. Enterotoxicity of Aeromonas hydrophila. f Med Microbiol 1977;10:317-23.

4 Cumberbatch N, Gurwith MJ, Langston C, Sack RB, Brunton JL. Cytotoxic enterotoxin produced by Aeromonas hydrophila: relationship of toxigenic isolates to diarrhoeal disease.' Infect Immun 1979;23:829-37.

${ }^{5}$ Rosner R. Aeromonas hydrophila as the etiologic agent in a case of severe gastroenteritis. Am $\mathcal{F}$ Clin Pathol 1964 ;42:402-4.

(Accepted 5 August 1980)

Departments of Medicine and Microbiology, Lister Hospital, Stevenage, Herts

A F M S RAHMAN, FRCPATH, consultant microbiologist

J M T WILLOUGHBY, DM, FRCP, consultant physician

\section{Lymphocyte sensitisation in nifedipine-induced hepatitis}

Nifedipine (Adalat) is a new, highly effective agent in the treatment of angina, with beneficial haemodynamic responses. ${ }^{1}$ Adverse side effects include gastrointestinal symptoms, sensation of heat, and facial flushing. We report on a patient who developed hepatitis after administration of nifedipine. The clinical course, immunological findings, and a positive challenge test result strongly indicated a hypersensitivity response.

\section{Case report}

A 69-year-old man with a history of myocardial infarction was treated with nifedipine, $40 \mathrm{mg}$ daily, because of severe, stable angina. Ten days after beginning the drug he experienced anorexia, nausea, and shaking chills with a temperature of $38.8^{\circ} \mathrm{C}$ and was admitted to hospital with painless jaundice. His blood pressure was $140 / 80 \mathrm{~mm} \mathrm{Hg}$ and pulse 100 beats/min. There was no

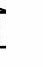
?

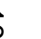
(1)

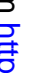

